\title{
A Practical Questionnaire and Literature Review: Dose Suzuki Grading Still the Gold Standard for the Diagnosis of Moyamoya Disease?
}

\section{YanChang Wei}

Beijing Tiantan Hospital, Capital Medical University

\section{ShiHao He}

Beijing Tiantan Hospital, Capital Medical University

ZiQi Liu

Beijing Tiantan Hospital, Capital Medical University

\section{CunXin Tan}

Peking University International Hospital

\section{ShuSen Qin}

Beijing Tiantan Hospital, Capital Medical University

Rong Wang ( $\sim$ ronger090614@126.com )

Beijing Tiantan Hospital https://orcid.org/0000-0002-0669-9321

\section{Research Article}

Keywords: Moyamoya disease, Suzuki grading, Practice survey, Method clinical

Posted Date: May 6th, 2021

DOI: https://doi.org/10.21203/rs.3.rs-317762/v1

License: (1) This work is licensed under a Creative Commons Attribution 4.0 International License. Read Full License 


\section{Abstract}

The traditional grading method of moyamoya disease represented by Suzuki grading system has always been the gold standard for most neurosurgeons in the diagnosis of moyamoya disease. However, in recent years, more and more studies have raised questions about Suzuki grading. The purpose of this study is to describe and summarize the questions raised about the Suzuki grading and reconsider its authority, using a questionnaire and literature review. The questionnaire showed that $73.61 \%$ of neurosurgeons had questioned the Suzuki grading, among which the main problems included "unclear boundaries between grades" and "inconsistent grading between the left and right cerebral hemispheres". From December 1969 to March 2021, 105 of the 773 references raised the same questions as in the questionnaire, and 27 of the 773 references raised different questions. Some of the questioned studies hope to take multiple imaging methods into consideration for grading of moyamoya disease, and some of the studies hope to include more quantifiable imaging indicators and establish a new grading system for moyamoya disease. In summary, the clinical utility of the Suzuki grading has been questioned by most neurosurgeons and some researchers, part of the research put forward some pertinent opinions.

\section{Introduction}

Moyamoya disease (MMD) is a chronic progressive cerebral arterial ischemic disease characterized by progressive stenosis or unilateral or bilateral occlusion of the internal carotid artery and uncontrolled compensatory proliferation of "cloud" vessels(Shang, Zhou et al. 2020). Its etiology is not yet clear. The incidence of MMD is low ( 0.09 per 100,000 people) in North America and other regions and high ( 0.94 per 100,000 people -2.3 per 100,000 people) in East Asia, especially in provinces such as Shandong and Henan in China and some coastal areas in Japan with obvious family clustering(Bao, Wang et al. 2019, Ahn, Park et al. 2014, Kainth, Chaudhry et al. 2013, Baba, Houkin et al. 2008). Early symptoms of MMD are not obvious, but the risk of stroke in advanced patients is very high, so it is very important for neurosurgeons to accurately diagnose and grade MMD patients(Zhao, Deng et al. 2018).

Since Suzuki grading was proposed by Suzuki et al in the 1960s, it has gradually become the main means for neurosurgeons around the world to diagnose and classify MMD. According to the change characteristics of internal and external carotid arteries in patients with MMD in digital subtraction angiography (DSA), as well as the characteristic changes of vascular network in the brain base, patients with MMD were divided into six stages by Suzuki stage(Suzuki and Takaku 1969). Although DSA is the gold standard for the diagnosis and grading of MMD, the familiarity of neurosurgeons with MMD and their understanding of Suzuki grading also affect the final diagnosis and treatment results. There has not been a comprehensive summary of the questions raised about the Suzuki grading system, nor has there been a summary of the better suggestions for these questions. The purpose of this study is to observe the subjective impression and application of Suzuki grading system by clinicians in various professional fields through a questionnaire survey, and to review the recent studies that questioned Suzuki grading or proposed new grading methods for MMD.

\section{Materials And Methods}

\section{Survey Design}


From February to June 2020, physicians from Beijing Tiantan Hospital, Peking Union Medical College Hospital, Peking University Hospital, and other large hospitals with high authority in the field of neurosurgery were invited to complete an online survey. The survey was prepared and published through a web-based anonymous survey platform (WJx.cn). The interviewees were mainly Chief Surgeon, Attending Surgeon, Resident, Continuing Doctor or Master/PhD candidate. This survey will focus on the responses of neurosurgeons in various specialties, including those specializing in cerebrovascular diseases or neurointerventional therapy, and other neurosurgical fields. In order to accurately locate and classify the respondents, we set a series of basic information questions, including respondents' age, familiarity with MMD/Suzuki grading, subjective impression of MMD/Suzuki grading and so on. In the main part of this study, seven groups of DSA image data of patients with MMD were set and the options from Level 1 to Level 6 were set. The judgments made by neurosurgeons in various professional fields were mainly observed. In addition, in order to guarantee the validity of the paper, we will be the first problem set grading tests suzuki access standards for testing, (Fig. 1), from the perspective of DSA images, visible: the end of the internal carotid artery occlusion, cerebral artery and middle cerebral artery imaging before bad, skull base (circulating blood vessels) and posterior circulation obvious smoke sample blood vessels. The above signs were in line with the characteristics of Suzuki grading level 3 and 4, and were verified by Dr. Wang and Dr. Qin to determine(Shang, Zhou et al. 2020, Suzuki and Takaku 1969). (Table 1) 
Table 1

Distributed Online Survey

\begin{tabular}{|l|l|}
\hline $\begin{array}{l}\text { Question } \\
\text { Basic questions and } \\
\text { impressions }\end{array}$ & Alternative answers \\
\hline $\begin{array}{l}\text { 1.Your age is? } \\
\text { 2.What is your area }\end{array}$ & $\begin{array}{l}\text { cerebrovascular disease/nerve intervention treatment/ neuroimaging/ } \\
\text { comprehensive treatment in diseases of the nervous system and other related } \\
\text { fields in neuroscience }\end{array}$ \\
\hline $\begin{array}{l}\text { 3.What is the number } \\
\text { of moyamoya } \\
\text { surgery performed by } \\
\text { your team every } \\
\text { year? }\end{array}$ & $0-30 / 30-100 / 100-200 / 200-300 />300$ \\
\hline $\begin{array}{l}\text { 4. Do you often } \\
\text { contact patients with } \\
\text { MMD in your daily } \\
\text { work? }\end{array}$ & Hardly/often/frequently \\
\hline
\end{tabular}

Impression of Suzuki

grading
5. Do you often use Hardly/often/frequently
Suzuki grading in
your work?
6. What do you think explaining the condition/diagnosing MMD/ choosing treatment/ analyzing is the function of
prognosis/ analyzing etiology/ and the value of academic discussion Suzuki grading?

\section{Have you Yes/No questioned the Suzuki grading?}

8. What questions have you raised about the Suzuki grading?

grading of nonlinear changes/ were not associated with clinical manifestations/ boundaries between unknown at all levels/ lack of therapeutic value/lack of scientific value/ not reflect disease progression/ lack of prognostic value and grade of the brain hemispheres appear inconsistent

\section{Suzuki grading test}

\section{Question9-15}

What grade of patient do you think this is in Suzuki?

\section{Level 1 - Level 6}

(See Annex 1 for detailed information)

Table 1 annotation: $₫$ Questions by this question respondents is not necessarily a professional field of degree, and diversified and neurosurgical treatment in clinical and research the integration of today, we set this issue to uncertain item choice, people can choose according to their working experience area.『ln our opinion, the Suzuki grading was not designed for a specific purpose, so the answer to this question is still a multiple-choice option.खWe will according to the existing study, common, about neurosurgeons or researchers put forward 
opinions and question of suzuki summary in this problem, the same, this problem still accept multiple choice(Jiang, Yang et al. 2018, Zhao, Deng et al. 2018, Kim, Bang et al. 2017, Deng, Gao et al. 2018).

\section{Selection Criteria}

The first question in the Suzuki grading test is the inclusion criteria of the questionnaire, which is very representative. The purpose of this question is to test the basic ability of the subjects to diagnose MMD. The images showed that this case had characteristic signs of terminal internal carotid artery stenosis/occlusion, poor imaging of the anterior and middle cerebral arteries, and obvious smoky vessels in the skull base. According to the Suzuki grading, this question is the standard Grade 3 sign of MMD, and may be Grade 4 . We have eliminated the failed answers to the standard questions. (Fig. 1)

\section{Search Strategy}

In this study, all original articles, literature reviews, case reports and letters to editors on PubMed and Google Scholar regarding grading methods of MMD were retrieved. In addition, the literature retrieved and its references or reviews were screened. Key words: "MMD/MMD grading", "suzuki grading", "MMD/MMD" (phrase or combination). We only included patients with MMD who had been grading by traditional grading methods or new methods, and provided questions and solutions for traditional grading methods of MMD in the literature. In this study, the literatures with complete cohort study verification experiments are preferred. When several studies put forward similar viewpoints, literatures with more cases are preferred. For specific literature screening principles, refer to Fig. 2.

\section{Statistical Analyses}

All data were collected through the online survey platform and exported to SPSS statistics, version 21.0 (IBM, Armonk, New York, USA). The descriptive statistics and tests were performed using Fisher's exact test. P-values of $<0.05$ were considered significant. The meta-analysis was conducted using Review Manager (RevMan) version 5.2 .

\section{Results}

\section{The questionnaire survey}

Our questionnaire was sent to clinicians in more than ten authoritative neurosurgery hospitals in China, and 466 valid questionnaires were collected. Those with excessive deviation were removed as not meeting the admission criteria of Suzuki grading test, and then we obtained a total of 341 Suzuki grading test answers. There was no significant difference in the frequency of use of Suzuki grading among specialized fields $\varangle \mathrm{P}>0.05 \rrbracket$. In terms of subjective impression, most of the respondents have questioned the Suzuki grading (73.61\%). The most focused questions is “Boundaries between unknown at all levels" $₫ 67.33 \%$ \and "Grade of the brain hemispheres appear inconsistent” $₫ 52.99 \%$. $\otimes T a b l e 2 \rrbracket$ 
Table 2

Basic information and subjective impression survey results

\begin{tabular}{|c|c|c|}
\hline Date & $N(\%)$ & Total $\mathbf{n}$ \\
\hline \multicolumn{3}{|l|}{ Old } \\
\hline$<30$ & $38(11.14 \%)$ & \multirow[t]{3}{*}{341} \\
\hline $30-50$ & $274(80.35 \%)$ & \\
\hline$>50$ & $29(8.51 \%)$ & \\
\hline \multicolumn{3}{|l|}{ Area of expertise } \\
\hline Cerebrovascular disease & $266(57.08 \%)$ & \multirow[t]{4}{*}{341} \\
\hline Nerve intervention treatment & $122(26.18 \%)$ & \\
\hline Neuroimaging & $14(3.01 \%)$ & \\
\hline Other Areas Of Neurosurgery & $64(13.73 \%)$ & \\
\hline \multicolumn{3}{|c|}{ Number of operations for MMD (per year) } \\
\hline$<30$ & $249(73.02 \%)$ & \multirow[t]{3}{*}{341} \\
\hline $30-300$ & $65(19.06 \%)$ & \\
\hline$>300$ & $27(7.92 \%)$ & \\
\hline \multicolumn{3}{|c|}{ How often do you diagnose patients with MMD? } \\
\hline Hardly & $157(46.04 \%)$ & \multirow[t]{3}{*}{341} \\
\hline Often & $109(31.96 \%)$ & \\
\hline Frequently & $75(22.00 \%)$ & \\
\hline \multicolumn{3}{|l|}{ Use Suzuki grading frequencies } \\
\hline Hardly & $165(48.39 \%)$ & \multirow[t]{3}{*}{341} \\
\hline Often & $119(34.89 \%)$ & \\
\hline Frequently & $57(16.72 \%)$ & \\
\hline \multicolumn{3}{|l|}{ Suzuki grading for what purpose } \\
\hline Explaining The Condition & $211(61.88 \%)$ & \multirow[t]{6}{*}{341 See Table Notes for details1. } \\
\hline Diagnosing MMD & $209(61.29 \%)$ & \\
\hline The Value Of Academic Discussion & $193(57.60)$ & \\
\hline Choosing Treatment & 195(57.18) & \\
\hline Analyzing Prognosis & $167(48.97)$ & \\
\hline Analyzing Etiology & $82(24.05)$ & \\
\hline
\end{tabular}




\begin{tabular}{|c|c|c|}
\hline Date & $N(\%)$ & Total $\mathbf{n}$ \\
\hline \multicolumn{3}{|l|}{ Have you ever questioned the Suzuki grading } \\
\hline Yes & $251(73.61)$ & \multirow[t]{2}{*}{341} \\
\hline No & $90(26.39)$ & \\
\hline \multicolumn{3}{|c|}{ What do you think are the shortcomings of Suzuki grading } \\
\hline Boundaries between unknown at all levels & $169(67.33)$ & \multirow[t]{8}{*}{251 See Table Notes for details2 } \\
\hline Grade of the brain hemispheres appear inconsistent & 133(52.99) & \\
\hline Were not associated with clinical manifestations & 107(42.63) & \\
\hline Grading Of Nonlinear Changes & $91(36.25)$ & \\
\hline Not reflect disease progression & $88(35.06)$ & \\
\hline Lack of prognostic value & $86(34.26)$ & \\
\hline Lack of therapeutic value & $58(23.11)$ & \\
\hline Lack of scientific value & $56(22.31)$ & \\
\hline
\end{tabular}

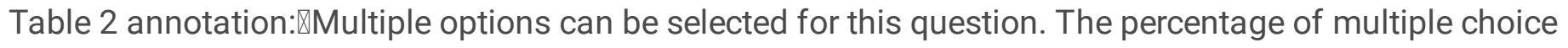
options $=$ the number of times the option was selected $\div$ the number of valid copies of the answer. The number of people who choose this option is the proportion of all the people who fill in this option. So, for multiple choice questions the percentage can add up to more than 100 percent. For example, 10 people filled in $A$ multiple choice question, of which 6 chose A, 5 chose B, and 3 chose C. So $60 \%$ choose A, $50 \%$ choose B, and $30 \%$ choose $C$. Three percentages add up to $140 \%$. $\otimes$ This question can only be answered by those who chose "Yes" in the previous question, so the total number of answers is 251 , and this question is also multiple choice.

\section{Suzuki grading test}

Table 3

The results of Suzuki grading application test

\begin{tabular}{|lllllllll|}
\hline & Level 1 & Level 2 & Level 3 & Level 4 & Level 5 & Level 6 & V & CV \\
\hline 1 & $0(0)$ & $0(0)$ & $204(59.82)$ & $137(40.18)$ & $0(0)$ & $0(0)$ & 1.069 & 31.83 \\
\hline 2 & $5(1.47)$ & $25(7.33)$ & $44(12.90)$ & $127(37.24)$ & $123(36.07)$ & $17(4.99)$ & 1.449 & 30.23 \\
\hline 3 & $7(2.05)$ & $17(4.99)$ & $21(6.16)$ & $46(13.49)$ & $148(43.40)$ & $102(30.01)$ & 1.765 & 28.96 \\
\hline 4 & $4(1.17)$ & $25(7.33)$ & $55(16.13)$ & $79(23.17)$ & $99(29.03)$ & $79(23.17)$ & 1.665 & 29.65 \\
\hline 5 & $10(2.93)$ & $23(6.74)$ & $17(4.99)$ & $59(17.30)$ & $108(31.67)$ & $124(36.37)$ & 1.749 & 27.88 \\
\hline 6 & $10(2.93)$ & $42(12.32)$ & $91(26.69)$ & $83(24.34)$ & $64(18.77)$ & $51(14.95)$ & 1.906 & 33.84 \\
\hline 7 & $3(0.88)$ & $25(7.33)$ & $69(20.23)$ & $96(28.15)$ & $85(24.93)$ & $63(18.48)$ & 1.707 & 30.31 \\
\hline
\end{tabular}

Table 3 annotation: This part is a single choice, and subjects need to choose from Level 1 to Level 6 based on their own clinical experience. All subjects will submit the answer sheet within 6 hours after receiving the answer 
sheet. The images provided for all the questions in this question are shown in Annex I.

Abbreviations: V, variance; CV, Coefficient of variation;1-7, First to seventh Suzuki grading test questions

\section{Analysis of the literature}

We reviewed English language medical literature published in PubMed and Google Scholar databases from December 1969 to March 2021 and included 774 articles that met our study criteria. Table 4 summarize the basic research contents of these literatures and the viewpoints similar to those of this study. Among all the reviewed literatures (a total of 774), a total of 308 literatures involved the traditional classification method of MMD/Suzuki classification method. Among them, 105 literatures raised questions in the questionnaire, and 27 literatures raised different questions. In addition, Table 5 summarizes the literatures with a large number of cases, complete verification experiments and representative opinions.

Table 4

The basic content and the related content summary in the literature

\begin{tabular}{|c|c|c|c|c|c|c|}
\hline & $\begin{array}{l}\text { Therapeutic } \\
\text { related class }\end{array}$ & $\begin{array}{l}\text { Prognostic } \\
\text { related class }\end{array}$ & $\begin{array}{l}\text { Clinical } \\
\text { methods } \\
\text { related class }\end{array}$ & $\begin{array}{l}\text { Basic } \\
\text { Research }\end{array}$ & other & Total(n) \\
\hline $\begin{array}{l}\text { Suzuki grading is } \\
\text { involved }\end{array}$ & 116 & 79 & 17 & 23 & 73 & 308 \\
\hline $\begin{array}{l}\text { Questions in the } \\
\text { questionnaire } \\
\text { is involved }\end{array}$ & 32 & 27 & 15 & 7 & 24 & 105 \\
\hline Total(n) & 239 & 147 & 39 & 144 & 205 & 774 \\
\hline \multicolumn{7}{|c|}{ The number of literatures raising questions about Suzuki grading } \\
\hline Date & & \multicolumn{2}{|c|}{$\mathrm{N}$} & \multicolumn{3}{|l|}{ Total $n$} \\
\hline \multicolumn{2}{|c|}{$\begin{array}{l}\text { Grade of the brain hemispheres appear } \\
\text { inconsistent }\end{array}$} & \multicolumn{2}{|l|}{17} & \multirow[t]{7}{*}{105} & & \\
\hline \multicolumn{2}{|c|}{$\begin{array}{l}\text { Were not associated with clinical } \\
\text { manifestations }\end{array}$} & \multicolumn{2}{|l|}{6} & & & \\
\hline \multicolumn{2}{|c|}{ Grading Of Nonlinear Changes } & \multicolumn{2}{|l|}{5} & & & \\
\hline \multicolumn{2}{|c|}{ Lack of therapeutic value } & \multicolumn{2}{|l|}{4} & & & \\
\hline \multicolumn{2}{|c|}{ Lack of prognostic value } & \multicolumn{2}{|l|}{3} & & & \\
\hline \multicolumn{2}{|c|}{ Lack of scientific value } & \multicolumn{2}{|l|}{3} & & & \\
\hline \multicolumn{2}{|c|}{ Not reflect disease progression } & \multicolumn{2}{|l|}{2} & & & \\
\hline \multicolumn{2}{|l|}{ other questions } & \multicolumn{2}{|l|}{27} & \multicolumn{3}{|l|}{27} \\
\hline
\end{tabular}


Table 5

The questions and inadequacies raised in the study and the relevant solutions

\begin{tabular}{|c|c|c|c|c|}
\hline Reference & $\begin{array}{l}\text { Ischemic/Hemorrhagic/ } \\
\text { asymptomatic MMD }\end{array}$ & $\begin{array}{l}\text { Adult/Child } \\
\text { MMD }\end{array}$ & $\begin{array}{l}\text { Questions or } \\
\text { shortcomings raised }\end{array}$ & The solution \\
\hline $\begin{array}{l}\text { Zhao J(Zhang, } \\
\text { Zhang et al. 2016) }\end{array}$ & $\mathrm{I}$ and $\mathrm{H}$ & Both & $\begin{array}{l}\text { Difficulty in assessing } \\
\text { stroke risk factors and } \\
\text { conditions }\end{array}$ & $\begin{array}{l}\text { Review cases } \\
\text { and make } \\
\text { systematic } \\
\text { improvements }\end{array}$ \\
\hline $\begin{array}{l}\text { P } \\
\text { Vajkoczy(Czabanka, } \\
\text { Pena-Tapia et al. } \\
\text { 2011) }\end{array}$ & I & $A$ & $\begin{array}{l}\text { Limited clinical } \\
\text { application }\end{array}$ & $\begin{array}{l}\text { Key } \\
\text { parameters } \\
\text { were } \\
\text { identified } \\
\text { through } \\
\text { prospective } \\
\text { studies and } \\
\text { the grading } \\
\text { system was } \\
\text { re-established }\end{array}$ \\
\hline $\begin{array}{l}\text { Satoshi } \\
\text { Kuroda(Kashiwazaki, } \\
\text { Akioka et al. 2017) }\end{array}$ & Both & Both & $\begin{array}{l}\text { Lack of hemodynamic } \\
\text { explanation }\end{array}$ & $\begin{array}{l}\text { Multiple } \\
\text { imaging } \\
\text { examinations } \\
\text { were used to } \\
\text { reconstruct } \\
\text { and validate } \\
\text { the system }\end{array}$ \\
\hline $\begin{array}{l}\text { Gary K. } \\
\text { Steinberg(Teo, } \\
\text { Furtado et al. 2020) }\end{array}$ & Both & Both & $\begin{array}{l}\text { Failure to reflect } \\
\text { hemodynamic } \\
\text { abnormalities and } \\
\text { poor } \\
\text { prognosis/treatment } \\
\text { reference significance }\end{array}$ & $\begin{array}{l}\text { Multiple } \\
\text { imaging } \\
\text { examinations } \\
\text { were used to } \\
\text { reconstruct } \\
\text { and validate } \\
\text { the system }\end{array}$ \\
\hline $\begin{array}{l}\text { Takashi } \\
\text { Yoshimoto(Houkin, } \\
\text { Nakayama et al. } \\
\text { 2005) }\end{array}$ & I & Both & $\begin{array}{l}\text { Based on invasive } \\
\text { inspection methods } \\
\text { and with risks }\end{array}$ & $\begin{array}{l}\text { A non- } \\
\text { invasive } \\
\text { inspection } \\
\text { method was } \\
\text { used to re- } \\
\text { establish the } \\
\text { system and } \\
\text { test its } \\
\text { correlation } \\
\text { with the } \\
\text { existing } \\
\text { system }\end{array}$ \\
\hline $\begin{array}{l}\text { Lian Duan(Liu, Han } \\
\text { et al. 2019) }\end{array}$ & Both & Both & $\begin{array}{l}\text { Individual differences } \\
\text { in collateral circulation } \\
\text { level were not } \\
\text { considered }\end{array}$ & $\begin{array}{l}\text { Review the } \\
\text { case, improve } \\
\text { the existing } \\
\text { system and } \\
\text { validate it }\end{array}$ \\
\hline
\end{tabular}




\begin{tabular}{|c|c|c|c|c|}
\hline Reference & $\begin{array}{l}\text { Ischemic/Hemorrhagic/ } \\
\text { asymptomatic MMD }\end{array}$ & $\begin{array}{l}\text { Adult/Child } \\
\text { MMD }\end{array}$ & $\begin{array}{l}\text { Questions or } \\
\text { shortcomings raised }\end{array}$ & The solution \\
\hline $\begin{array}{l}\text { Y.-F. Chen(Lin, Kuo et } \\
\text { al. 2019) }\end{array}$ & $\mathrm{I}$ and $\mathrm{H}$ & Both & $\begin{array}{l}\text { Grades are poorly } \\
\text { correlated with } \\
\text { symptoms and lack } \\
\text { therapeutic/prognostic } \\
\text { significance }\end{array}$ & $\begin{array}{l}\text { Prospective } \\
\text { study and } \\
\text { introduction } \\
\text { of new } \\
\text { imaging } \\
\text { methods, } \\
\text { reconstruction } \\
\text { and validation } \\
\text { of the system. }\end{array}$ \\
\hline $\begin{array}{l}\text { B. Jayanand } \\
\text { Sudhir(Kathuveetil, } \\
\text { Sylaja et al. 2020) }\end{array}$ & $\mathrm{I}$ and $\mathrm{H}$ & Both & $\begin{array}{l}\text { Imaging findings are } \\
\text { difficult to distinguish } \\
\text { from other ischemic } \\
\text { diseases }\end{array}$ & $\begin{array}{l}\text { The system } \\
\text { was rebuilt } \\
\text { and the queue } \\
\text { comparison } \\
\text { was verified }\end{array}$ \\
\hline $\begin{array}{l}\text { Cheng-Yen } \\
\text { Chang(Hung, Liang } \\
\text { et al. 2014) }\end{array}$ & I & A & $\begin{array}{l}\text { lack of } \\
\text { dynamic/continuous } \\
\text { change between } \\
\text { grades and it is } \\
\text { difficult to reflect small } \\
\text { changes }\end{array}$ & $\begin{array}{l}\text { Prospective } \\
\text { studies, } \\
\text { introducing } \\
\text { new imaging } \\
\text { methods and } \\
\text { concepts, and } \\
\text { improving } \\
\text { and validating } \\
\text { existing } \\
\text { systems }\end{array}$ \\
\hline
\end{tabular}

Abbreviations: I, ischemic; $\mathrm{H}$, hemorrhagic; $\mathrm{A}$, adult; $\mathrm{C}$, child

\section{Discussion}

In 1969, Suzuki et al. proposed the traditional classification method of MMD based on DSA, which is still regarded as the gold standard for diagnosis of MMD by many studies. However, both from our questionnaire results and literature review, the limitations of Suzuki grading at the beginning of the design and the irrationality in the process of use have gradually aroused the thinking of the majority of neurosurgeons.

\section{The interobserver reliability of the questionnaire results}

Most neurosurgeon want to work through the use of a variety of clinical grading suzuki, such as "condition" (61.88\%), "diagnosis MMD" (61.29\%), there are more than half of the neurosurgeon will suzuki grading for "academic discussion" (57.60\%), which can be good, traditional classification methods of MMD, seems to be no need for the "gold standard" too much to discuss.

However, our survey results show that most neurosurgeons (73.61\%) have questioned the Suzuki grading, the focus of which is "unclear boundaries between grades" and "inconsistent grading between the left and right cerebral hemispheres". Many literatures believe that clear clinical grading is helpful for neurosurgeons to make better treatment plans for patients with MMD and is also helpful for the analysis of prognosis(Wang, Qian et al. 2016, Rosi, Riordan et al. 2019, Deng, Gao et al. 2018). If neurosurgeons question whether the traditional grading method is competent for this role, it may have a negative impact on the treatment and prognosis of patients. In addition, with the deepening of researches on unilateral MMD, there is sufficient evidence to show 
that the two sides of the damaged cerebral hemispheres of some patients with unilateral MMD can present different grading signs, which was not considered at the beginning of the design of Suzuki grading(Church, Bell-Stephens et al. 2020, Hayashi, Horie et al. 2014, Gatti, Torriente et al. 2021).(Table2)

We set the Suzuki grading test questions, no one question answer more than half of the respondents choose. As can be seen from Figure 2 and Figure 3, since there is no clear quantitative standard, most interviewees can hardly distinguish the degree of posterior cerebral circulation stenosis in cases 2,4 and 7 . Therefore, when interviewees judge Suzuki grading in cases 2,4 and 7, there is almost no difference between grade 4 and grade 5.Similarly, the Suzuki grading did not clearly quantify the extent of the proliferation and dissipation of smoky blood vessels. In cases 3 and 6 , it was also difficult for respondents to make a judgment on levels 3 and 4 . (Fig2\Fig3)

The purpose of setting up the access question is to include a questionnaire of subjects with basic diagnostic ability of MMD. The imaging findings presented in this topic were highly consistent with the Suzuki grading's Level 3 definition, and subjects only needed to identify poorly developed anterior cerebral arteries, middle cerebral arteries, and sufficiently significant smoky vessels. However, in the original summary of the questionnaire results, only less than $50 \%$ of the 466 respondents chose Level 3 , and no less than $30 \%$ of the respondents believed that it met the definition of Level 4.The fourth and seventh test questions we set showed almost the same signs as the access question, with no more than half of the respondents choosing level 3 . Obviously, because there is no clear quantitative standard for Suzuki classification, the degree of hyperplasia of smoky blood vessels and the degree of internal carotid artery branch stenosis cannot be accurately assessed. Perhaps this is why the answers to our quiz questions are so widely distributed. (Table3)

\section{Literature review of grading methods for MMD}

Among the numerous literatures, the questions raised by researchers on the traditional grading methods of MMD have a high coincidence with the results of our questionnaire. "unclear boundaries between grades" and "inconsistent grading between the left and right cerebral hemispheres", the former more reflected in our literature review, most of the research puts forward a new grading method were think traditional grading methods for MMD, lack of quantifiable indicators to grading of imaging signs, these studies are also by introducing a new concept or imaging methods, rebuilding or improving grading system, most of their point of view has been clinical test and verify. Studies that review one hemisphere as a unit also raise the same questions that we found. Most of them use double-blind case reviews conducted by senior experts to make it easier to diagnose and grade both hemispheres as a whole(Table5). We found that neurosurgeons of different ages and fields of expertise had little difference in grading cases using the Suzuki grading system $(P>0.05)$, but there were significant differences in questions raised by neurosurgeons of different ages $(P<0.05)$. Therefore, we believe that there is little difference in the level of knowledge of the Suzuki grading method among the broad neurosurgeon community, perhaps because of the defects in the Suzuki grading system itself.

Our literature review also shows that there are more studies suggest that the traditional grading method of MMD clinical practicability, lack of the practical mainly includes: analysis of prognosis, explain the illness, to predict risk factors, our investigation, according to the results of clinical application, is the purpose of the neurosurgeon use grading system, perhaps the traditional grading methods for MMD don't have advantage and authority in this field. With the development of imaging technology, many researchers are not satisfied with 
only using a single, nonlinear method that cannot reflect hemodynamic changes to diagnose such a complex and progressive disease as MMD(Yamamoto, Okada et al. 2018, Ladner, Donahue et al. 2017, Ha, Choi et al. 2019). Moreover, the traditional grading method is based on invasive imaging methods, which may bring many complications. Numerous studies on the new grading of MMD have introduced a variety of more comprehensive, more linear, non-invasive imaging methods, and have introduced more quantifiable hemodynamic indicators and imaging markers. These new grading methods not only reconstruct or improve the existing grading system, but also get better clinical validation(Table5).

\section{New progress in grading methods of MMD}

In view of the limitations of Suzuki grading or DSA in the diagnosis of MMD, such as "the boundary between different grades is not clear", some studies based on a large number of patients with MMD image data, summarized and analyzed the easily found imaging markers or features, and finally reclassified the MMD grade according to the degree. Although the degree of stenosis is difficult to measure in the intracranial vessels with progressive ischemia, a clear cutoff point can be found. M. Czabanka et al. classified a large number of DSA images based on the presence or absence of stenosis/occlusion lesions, smoky vessels, and intracranial and extracranial compensation, and regarded DSA as only a basic objective basis, combining the presence or absence of MRI signs of ischemia, hemorrhage, atrophy, and whether cerebral vascular reserve volume (CVRC) reflected the phenomenon of blood steal(Czabanka, Pena-Tapia et al. 2011). The new method is no longer the highest DSA as the only or the weight of diagnosis, and proposes the concept of partial hemodynamic despite the increasing number of clinical examination project would bring something extra to the whole process of diagnosis and treatment of workload, but perhaps as MMD diagnosis efficiency, neurologic symptoms assessment of patients with MMD risk of a new type of MMD grading method(Jiang, Yang et al. 2018, Cho, Jo et al. 2017). Moreover囚the Berlin grading system, Czanbanka, put forward again to verify the reliability of using a variety of imaging techniques in the diagnosis of MMD, this kind of method based on magnetic resonance imaging (MRI) are of the utmost importance, single photon emission computed tomography (SPECT), and other means of hemodynamic relationship between damage and the incidence of cerebral ischemic lesions, the study is in the process of into the case is based on a single hemisphere unit, so that each hemisphere is likely to have different grading(Teo and Steinberg 2020, Yu, Zhang et al. 2020, Czabanka, Boschi et al. 2016). Berlin grading system, is considered the beginning of the design may appear "the brain hemispheres inconsistent grading", only to begin the design idea is better than the two hemispheres as a unified whole, more importantly, the study may be first consider differences in the incidence of target population, when as an object in the study to east Asian patients with MMD validation to make the corresponding changes(Teo, Furtado et al. 2020, Kashiwazaki, Akioka et al. 2017).

Some researches believe that Suzuki grading, as a traditional grading system for MMD, has a high popularity worldwide. Therefore, it is expected to design a new grading system based on the six grades of Suzuki grading. Lian Duan et al. summarized and reviewed the imaging data of a large number of patients with idiopathic MMD, reclassified the characteristic structure of MMD on the anatomical level, and established the disease severity grade with a relatively clear number stratified. In this study, based on the collateral network of posterior cerebral artery, anterior cerebral artery and middle cerebral artery in the delayed venous stage, the presence of retrograde blood flow in the above regions and blood supply in the cortical boundary region were analyzed, and all kinds of conditions were classified into the new type of MMD collateral circulation grading system on a

Page $12 / 20$ 
grading of 1-12 based on the corresponding Suzuki grading system. Anatomical abnormalities reflected in DSA by patients with MMD are the most intuitive and representative abnormalities. Explore the changes and differences of compensatory vessels in patients with various types of MMD, which may better explain why patients with the same Suzuki grade have different neurological symptoms, that is, solve the problem of "grading is not consistent with clinical symptoms". Although the main and branch vascular abnormalities and various brain parenchymal abnormalities in patients with MMD should be taken into account by the new grading system, studies based on collateral circulation are relatively basic(Rosi, Riordan et al. 2019, Ladner, Donahue et al. 2017, Hwang, Cho et al. 2020, Liu, Han et al. 2019).

Most neurosurgical clinicians routinely use DSA and MRI as the diagnosis and grading means of MMD. However, studies in recent years have shown that the use of multimodal imaging means can enable clinicians to obtain more risk prediction information, and can also better summarize the pathogenesis factors and symptoms of MMD. Based on noninvasive arterial and venous phase, for example, CTP - Sis of MMD grading system, not only has the advantage of noninvasive, convenient, and in the evaluation of unilateral MMD in or out of the blood group MMD has the superiority, such research, with the help of the collateral vessels in blood both in arterial and venous phase flow more slowly, and is verified with the help of the DSA technique and revision, with lower layers spiral CT scanner to rapid and continuous scanning, finally to difference in the level of regional cortical blood vessels are damaged, the damaged brain hemispheres are divided into more interested in area, The severity of the disease was classified by ischemia range, ischemia duration and radiographic integrity in these areas. Such studies, although not completely out of the suzuki grading or the restrictions of DSA technology, but for the traditional checking method provides a different perspective, MMD and postoperative risk assessment is helpful for clinical doctors, neural function damage assessment, and a kind of noninvasive and efficient way of checking for the general clinical neurosurgery is a very ideal, it may also be the future major trends of diagnosis and grading of MMD and focus(Kathuveetil, Sylaja et al. 2020, Fan, Khalighi et al. 2019, Lin, Kuo et al. 2019, Nishizawa, Fujimura et al. 2020, Xue, Peng et al. 2019).

\section{Limitations and disadvantages}

Our questionnaire distribution scope is relatively limited, 341 of the answers passed the admission question we set, which seems a little weak for a large population of MMD like China. However, neurosurgeons especially full-time neurosurgeons in the field of cardiovascular disease, even in China is very few, and, this survey focused by many authoritative hospital neurosurgery almost covers all over the world the highest incidence of MMD area, namely the northern coastal areas and the central plains region, this greatly reduced the investigation and research of sampling error and system error. We did not validate the new grading methods or improved methods in the literature review, and the validation methods in the literature only included prospective validation on a small grading and sample size. Therefore, we cannot completely abandon the traditional grading method of MMD, nor can we completely apply the new grading method independently.

\section{Conclusion}

In conclusion, the clinical utility of the Suzuki grading system has been questioned by most Chinese neurosurgeons and a growing number of researchers. Questions have focused on the lack of strict grading standards and the lack of meeting specific clinical requirements. Comprehensive reference to more advanced

Page $13 / 20$ 
or non-invasive imaging examination methods can better diagnose and grade MMD. The diagnostic efficiency of MMD can be improved by defining more quantifiable imaging signs.

\section{Abbreviations}

MMD囚moyamoya disease

DSA: digital subtraction angiography

CVRC: cerebral vascular reserve volume

MRI: magnetic resonance imaging

SPECT: single photon emission computed tomography

CT: computerized tomography

\section{Declarations}

\section{Funding}

This study was supported by the Beijing Municipal Science \& Technology Commission (Z151100004015077DR) and by the Beijing municipal health system high-level health technical personnel training program (2015-3041-DR).

\section{Conflicts of interest}

The authors declare that they have no competing interests.

\section{Availability of data and material}

Data and material not provided in the article will be shared at the request of other investigators for purposes of replicating procedures and results. For data access, researchers can contact corresponding author.

\section{Code availability}

Not applicable

\section{Ethics approval}

Not applicable

\section{Consent to participate}

All participants agree to participate in this study

\section{Consent for publication}

This study is approved for publication 


\section{Authors' contributions}

YW and SH contributed equally to this work \they were responsible for the writing and revision of this paper and were the first authors of this study. ZL was responsible for the collection and collation of references in this study, CT and SQ were responsible for the data collation and analysis of this study, and WR was the corresponding author of this study and was responsible for the collation of this study.

\section{Acknowledgement}

The study authors thank all the Chinese neurosurgeons who participated in the survey, who have been working hard in areas with the highest incidence of moyamoya disease in the world.

\section{References}

1. Ahn, I. M., et al. (2014). "Incidence, prevalence, and survival of moyamoya disease in Korea: a nationwide, population-based study." Stroke 45(4): 1090-1095.

2. Baba, T., et al. (2008). "Novel epidemiological features of moyamoya disease." J Neurol Neurosurg Psychiatry 79(8): 900-904.

3. Bao, X. Y., et al. (2019). "Epidemiology of Moyamoya Disease in China: Single-Center, Population-Based Study." World Neurosurg 122: e917-e923.

4. Cho, H., et al. (2017). "Low flow velocity in the middle cerebral artery predicting infarction after bypass surgery in adult moyamoya disease." J Neurosurg 126(5): 1573-1577.

5. Church, E. W., et al. (2020). "Clinical Course of Unilateral Moyamoya Disease." Neurosurgery.

6. Czabanka, M., et al. (2016). "Grading of moyamoya disease allows stratification for postoperative ischemia in bilateral revascularization surgery." Acta Neurochir (Wien) 158(10): 1895-1900.

7. Czabanka, M., et al. (2011). "Proposal for a new grading of Moyamoya disease in adult patients." Cerebrovasc Dis 32(1): 41-50.

8. Deng, X., et al. (2018). "Effects of different surgical modalities on the clinical outcome of patients with moyamoya disease: a prospective cohort study." J Neurosurg 128(5): 1327-1337.

9. Fan, A. P., et al. (2019). "Identifying Hypoperfusion in Moyamoya Disease With Arterial Spin Labeling and an [(15)0]-Water Positron Emission Tomography/Magnetic Resonance Imaging Normative Database." Stroke 50(2): 373-380.

10. Gatti, J. R., et al. (2021). "Clinical Presentation and Stroke Incidence Differ by Moyamoya Etiology." J Child Neurol 36(4): 272-280.

11. Ha, J. Y., et al. (2019). "Arterial Spin Labeling MRI for Quantitative Assessment of Cerebral Perfusion Before and After Cerebral Revascularization in Children with Moyamoya Disease." Korean J Radiol 20(6): 985-996.

12. Hayashi, K., et al. (2014). "A nationwide survey on unilateral moyamoya disease in Japan." Clin Neurol Neurosurg 124: 1-5.

13. Houkin, K., et al. (2005). "Novel magnetic resonance angiography stage grading for moyamoya disease." Cerebrovasc Dis 20(5): 347-354. 
14. Hung, S. C., et al. (2014). "New grading of moyamoya disease using color-coded parametric quantitative digital subtraction angiography." J Chin Med Assoc 77(8): 437-442.

15. Hwang, I., et al. (2020). "Revascularization Evaluation in Adult-Onset Moyamoya Disease after Bypass Surgery: Superselective Arterial Spin Labeling Perfusion MRI Compared with Digital Subtraction Angiography." Radiology 297(3): 630-637.

16. Jiang, H., et al. (2018). "Long-Term Outcomes After Combined Revascularization Surgery in Adult Hemorrhagic Moyamoya Disease." World Neurosurg 116: e1032-e1041.

17. Kainth, D., et al. (2013). "Epidemiological and clinical features of moyamoya disease in the USA." Neuroepidemiology 40(4): 282-287.

18. Kashiwazaki, D., et al. (2017). "Berlin Grading System Can Stratify the Onset and Predict Perioperative Complications in Adult Moyamoya Disease." Neurosurgery 81(6): 986-991.

19. Kathuveetil, A., et al. (2020). "Vessel Wall Thickening and Enhancement in High-Resolution Intracranial Vessel Wall Imaging: A Predictor of Future Ischemic Events in Moyamoya Disease." American Journal of Neuroradiology 41(1): 100-105.

20. Kim, T., et al. (2017). "Hemodynamic Changes after Unilateral Revascularization for Moyamoya Disease: Serial Assessment by Quantitative Magnetic Resonance Angiography." Neurosurgery 81(1): 111-119.

21. Ladner, T. R., et al. (2017). "Prior Infarcts, Reactivity, and Angiography in Moyamoya Disease (PIRAMD): a scoring system for moyamoya severity based on multimodal hemodynamic imaging." J Neurosurg 126(2): 495-503.

22. Lin, Y. H., et al. (2019). "Standardized MR Perfusion Scoring System for Evaluation of Sequential Perfusion Changes and Surgical Outcome of Moyamoya Disease." AJNR Am J Neuroradiol 40(2): 260-266.

23. Liu, Z. W., et al. (2019). "Collateral Circulation in Moyamoya Disease: A New Grading System." Stroke 50(10): 2708-2715.

24. Nishizawa, T., et al. (2020). "Prediction of Cerebral Hyperperfusion after Superficial Temporal Artery-Middle Cerebral Artery Anastomosis by Three-Dimensional-Time-of-Flight Magnetic Resonance Angiography in Adult Patients with Moyamoya Disease." Cerebrovasc Dis 49(4): 396-403.

25. Rosi, A., et al. (2019). "Clinical status and evolution in moyamoya: which angiographic findings correlate?" Brain Commun 1(1): fcz029.

26. Shang, S., et al. (2020). "Progress in moyamoya disease." Neurosurg Rev 43(2): 371-382.

27. Suzuki, J. and A. Takaku (1969). "Cerebrovascular "moyamoya" disease. Disease showing abnormal netlike vessels in base of brain." Arch Neurol 20(3): 288-299.

28. Teo, M., et al. (2020). "Validation and Application for the Berlin Grading System of Moyamoya Disease in Adult Patients." Neurosurgery 86(2): 203-212.

29. Teo, M. and G. K. Steinberg (2020). "In Reply: Validation and Application for the Berlin Grading System of Moyamoya Disease in Adult Patients." Neurosurgery 87(2): E265.

30. Wang, L., et al. (2016). "Indirect Bypass Surgery May Be More Beneficial for Symptomatic Patients with Moyamoya Disease at Early Suzuki Stage." World Neurosurg 95: 304-308.

31. Xue, J., et al. (2019). "Preliminary application of CT perfusion source images for evaluating regional collateral circulation in unilateral Moyamoya disease." Quant Imaging Med Surg 9(4): 615-624. 
32. Yamamoto, T., et al. (2018). "Magnetic resonance angiography with compressed sensing: An evaluation of moyamoya disease." PLoS One 13(1): e0189493.

33. Yu, J., et al. (2020). "Letter: Validation and Application for the Berlin Grading System of Moyamoya Disease in Adult Patients." Neurosurgery 87(2): E264.

34. Zhang, Q., et al. (2016). "Clinical and Angiographic Features of Patients with Moyamoya Disease and the p.R4810K Heterozygous Variant." World Neurosurg 90: 530-538 e533.

35. Zhao, M., et al. (2018). "Risk factors for and outcomes of postoperative complications in adult patients with moyamoya disease." J Neurosurg: 1-12.

\section{Figures}
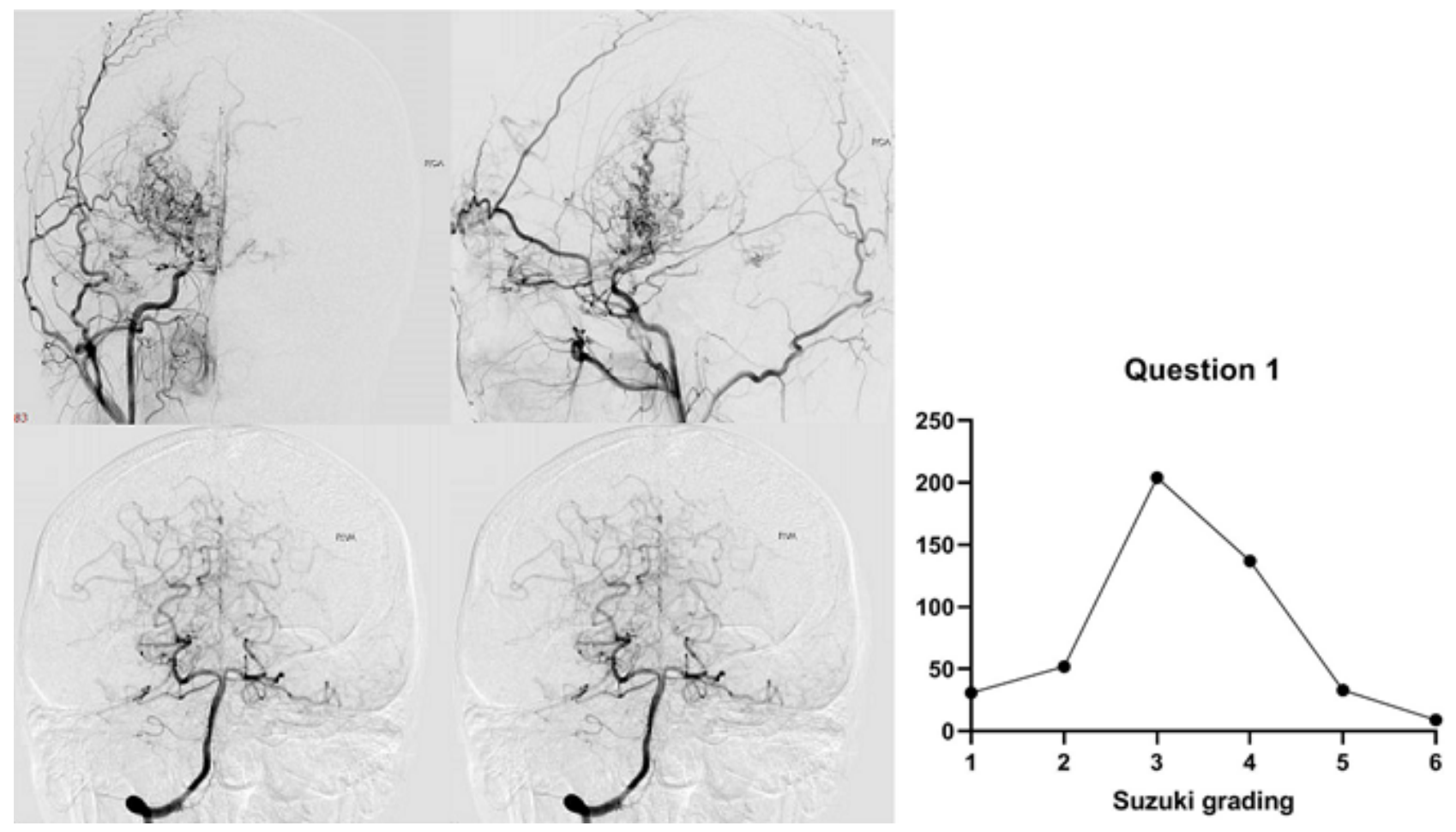

Figure 1

The first question in the Suzuki grading test is the inclusion criteria of the questionnaire, which is very representative. 
Search Suzuki grading, MMD and other key words

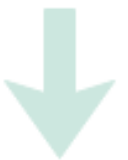

The remaining 773 related literatures were classified and summarized (Table4)

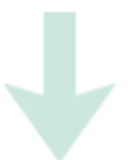

The basic contents and opinions of the remaining 9 literatures were summarized (Table5)

Figure 2

Search Strategy
Repetitive studies, low-correlation studies, and crossdisciplinary studies were excluded

Studies that propose new grading methods and have complete verification experiments are preferred. Studies with similar viewpoints and more cases are preferred 


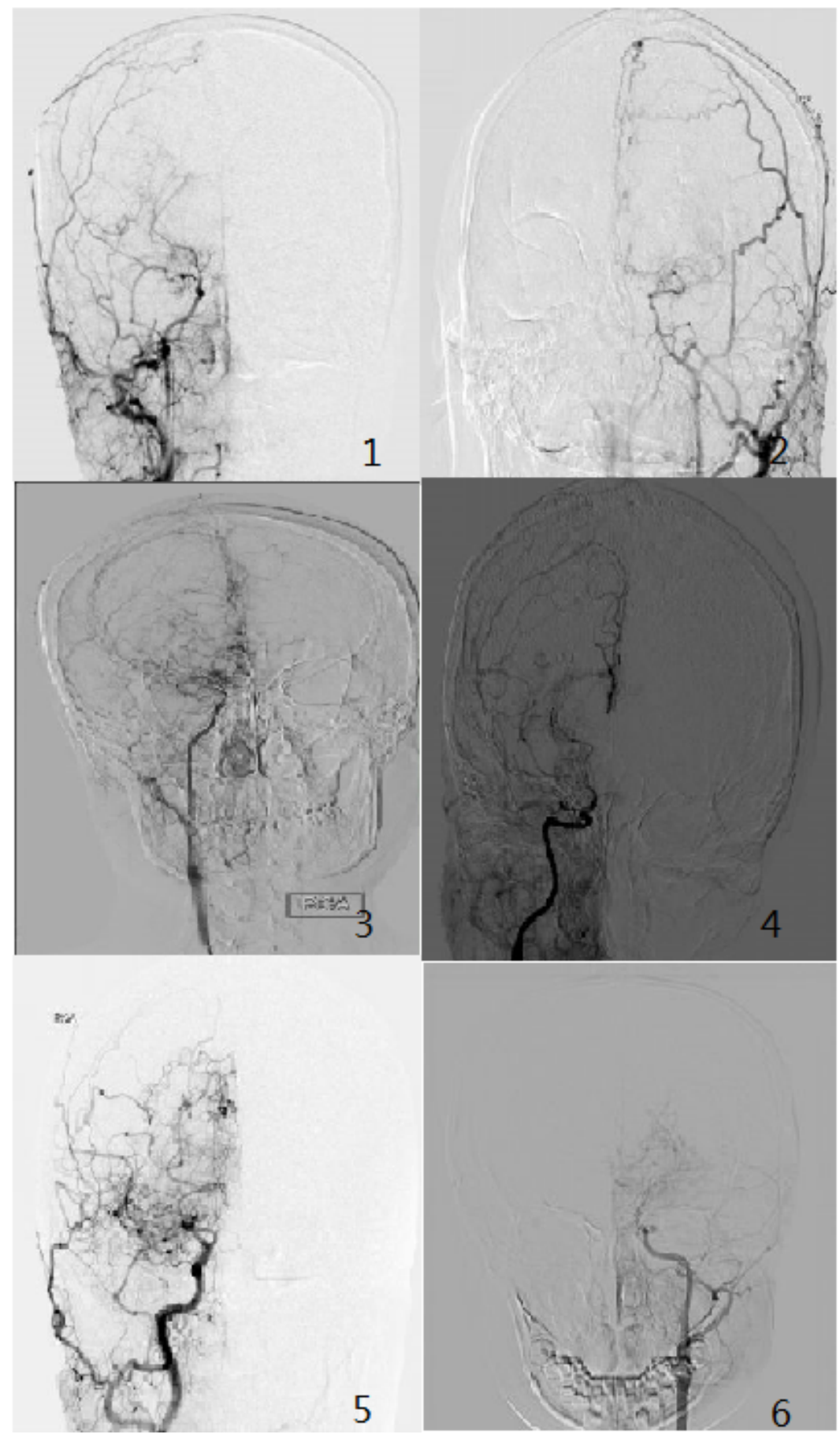

Figure 3

Suzuki grading test 
Question 2

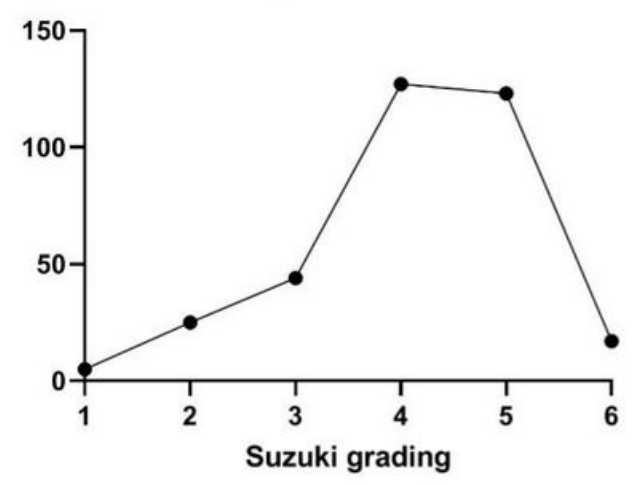

Question 4

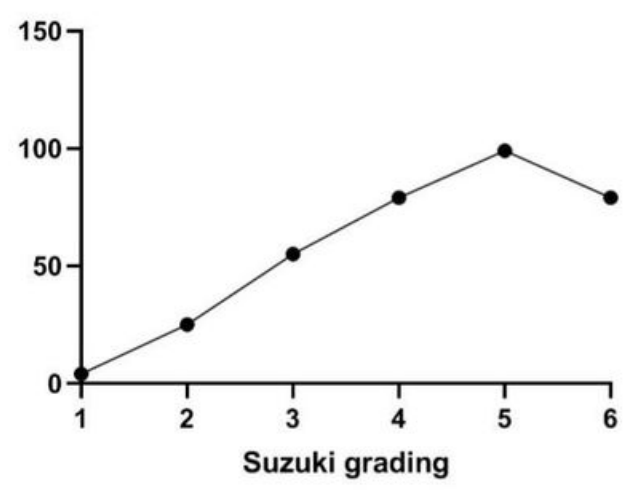

Question 6

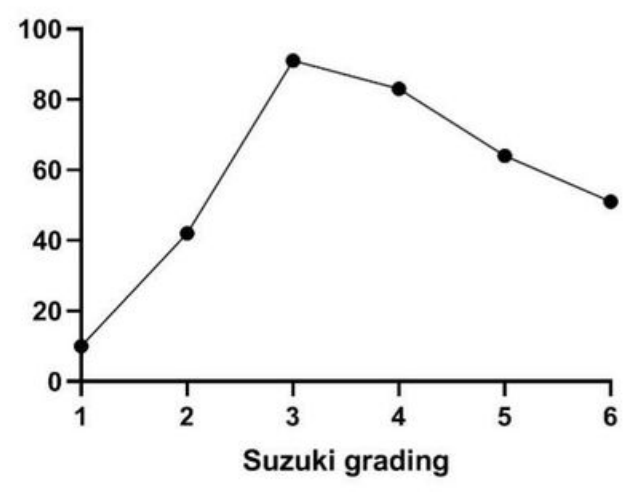

Question 3

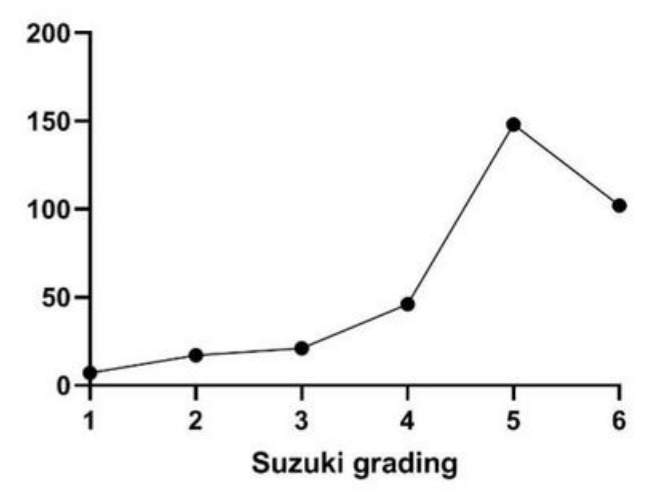

Question 5

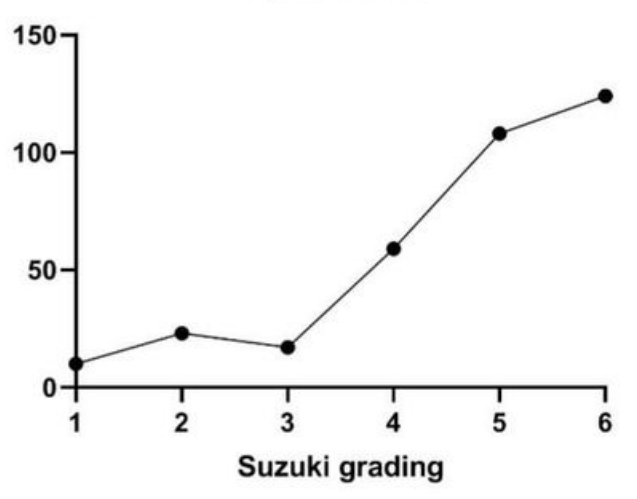

Question 7

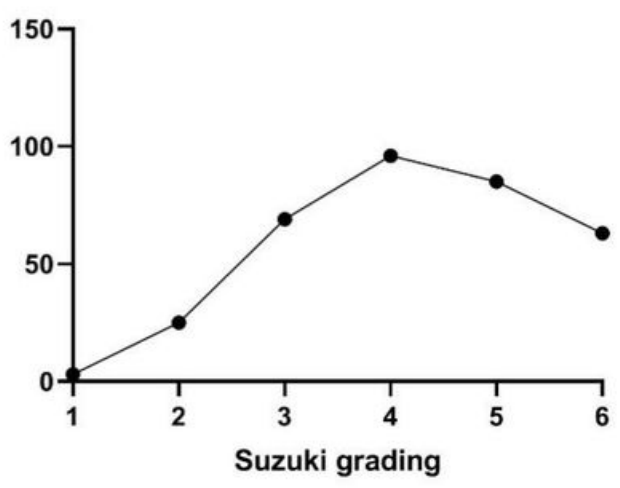

Figure 4

Suzuki grading test questions 